\title{
Features and mechanism of abrasive water jet cutting of Q345 steel
}

\author{
Xiaochen Chen, Jinfa Guan*, Songsheng Deng, Qiang Liu, Ming Chen \\ Department of Petroleum Supply Engineering, Army Logistics University of PLA, Chongqing 401331, China
}

Corresponding Author Email: gjfcg_928@163.com

https://doi.org/10.18280/ijht.360111

Received: 2 November 2017

Accepted: 12 January 2018

\section{Keywords:}

abrasive water jet (AWJ), smoothedparticle hydrodynamics (SPH), finiteelement method (FEM), erosion.

\begin{abstract}
This paper attempts to disclose the cutting features and mechanism of the pre-mixed abrasive water jet (AWJ) on Q345 steel. For this purpose, several cutting experiments were performed on the pre-mixed AWJ and a Q345 steel plate. Besides, a numerical simulation model was established based on the smoothed-particle hydrodynamics (SPH) and finite-element method (FEM) and adopted to analyse the erosion features of the jet at different angles and pressures. The main conclusions are as follows: (1) There exists a pressure threshold, i.e. the jet pressure under which the abrasive erosion kinetic energy is just enough to induce material deformation. For the 80 mesh corundum abrasive particles, the pressure threshold of Q345 steel is 15 17MPa. (2) The Q345 steel suffers from deformation and failure under the high-frequency and high-speed impinging of abrasive particles. The abrasive velocity is positively correlated with the erosion ability of the abrasive particles to induce material failure. (3) The variation in the jet angle changes the vertical and horizontal jet velocities and affects the erosion process of the jet. (4) For Q345 steel, the optimal jet angle is about $80^{\circ}$. At this angle, the jet deflection trend towards the non-material side is minimized without undermining the jet erosion ability in the vertical direction. The research findings provide new insights into the mechanism of the AWJ cutting.
\end{abstract}

\section{INTRODUCTION}

As an emerging cutting technique, abrasive water jet (AWJ) has been successfully applied to the cutting of various materials, such as ceramics, titanium and composites [1-5]. The widening of the application scope is calling for higher precision of AWJ cutting. To answer the call, it is necessary to fully understand the erosion of materials under the action of abrasive particles [6]. Thus, much research has been done on the features and mechanism of AWJ cutting.

Previous studies have shown that the jet is mainly affected by cutting parameters and material properties [7-8]. Among them, the cutting parameters include the cutting pressure, standoff distance, traverse rate, abrasive concentration and jet angle [9]. The effects of these parameters on the AWJ cutting of different materials were experimentally investigated by Gupta [10], Billingham [11], Aich [12] and Löschner [13]. Nonetheless, it is difficult to identify the exact effects through experiments due to the high-speed micro erosion during the AWJ cutting [14]. To overcome the difficulty, some scholars have examined the AWJ cutting process of transparent materials by high-speed photography. However, this technique can not be applied to opaque materials [15].

To make up for the limitations of experimental research, numerical simulation has also been adopted to explore the dynamic erosion of materials [16]. For instance, Azimian et al. [17] employed the Lagrange method to simulate the material erosion. But calculation divergence often occurs because of mesh distortion of the jet. Considering the deformation issue, some scholars have performed mesh-free simulations [18]. Lin et al. [19] discussed the erosion process of rock by the smoothed-particle hydrodynamics (SPH) method and obtained lots of data that cannot be acquired through experiments. The SPH was also used by Deng et al. [20] to simulate the erosion at different angles and proved more accurate than the traditional finite-element simulation.

In light of the above, this paper attempts to disclose the cutting features and mechanism of the pre-mixed AWJ on Q345 steel. To this end, a numerical simulation model was established based on the SPH coupled FEM and applied to analyse the interaction between the jet and the material, as well as the erosion mechanism of the steel plate. The purpose is to provide new insights into the mechanism of the AWJ cutting.

\section{PRE-MIXED AWJ CUTTING EXPERIMENT}

\subsection{Experiment system}

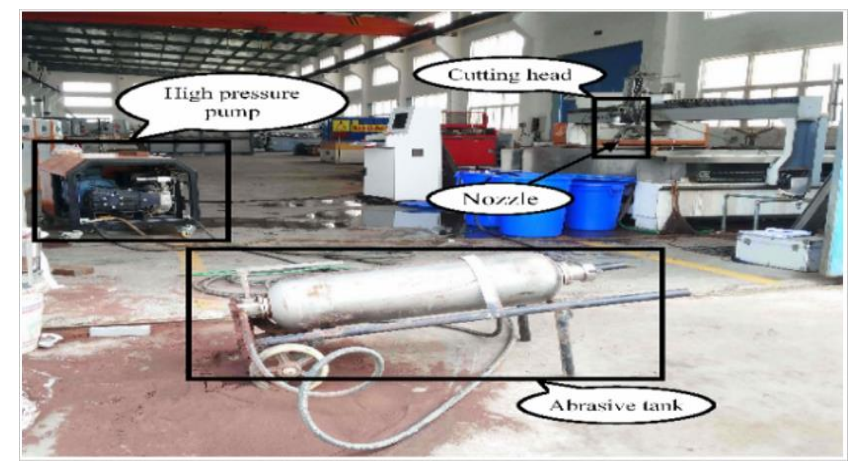

Figure 1. The experiment system 
The experiments were performed on a pre-mixed AWJ cutting system, which consists of a high-pressure (HP) pump, an abrasive tank, an AWJ nozzle, and several HP hoses (Figure 1) [21]. Below is a brief introduction to the operation process of the system.

First, the HP water generated by the HP pump is sent to the abrasive tank. At the tank bottom, the HP water is mixed with the abrasive particles. As the mixture flows out of the tank, the abrasive particles are gradually accelerated by the water. By the time the mixture reaches the nozzle inlet, the abrasive particles have been thoroughly mixed with the water and share the same velocity with the latter. Then, the mixture is accelerated at the nozzle and ejected from the nozzle outlet at a high speed, forming a high-speed AWJ.

During cutting experiments, the nozzle movement was controlled by the computer numerically controlled (CNC) machine tool. The standoff distance, traverse rate and nozzle angle were adjusted by the computer; the abrasive concentration was regulated by the abrasive tank; the pump pressure was controlled by reflux.

\subsection{Experiment design}

Several cutting experiments were conducted on a $45.0 \mathrm{~mm}$ thick Q345 steel plate to disclose the effects of cutting parameters on the cutting depth. The parameters include cutting pressure, traverse rate, standoff distance and jet angle. Table 1 lists the experiment parameters and their values.

Table 1. Experiment parameters and values

\begin{tabular}{c|c}
\hline Experiment parameter & Value \\
\hline Cutting pressure $(\mathrm{MPa})$ & $25,30,35,40,45$ \\
Traverse rate $(\mathrm{mm} / \mathrm{min})$ & $30,45,60,75,90$ \\
Jet angle $(\mathrm{deg})$ & $50,70,90,110,130$ \\
Standoff distance $(\mathrm{mm})$ & 4 \\
Diameter of nozzle outlet $(\mathrm{mm})$ & 1 \\
Abrasive volume concentration & $6 \%$ \\
\hline
\end{tabular}

On each cutting slit, four points were selected for depth measurement. The average value of the four measured results was taken as the cutting depth of the corresponding cutting slit.

\subsection{Effect of cutting pressure on slit depth}

The effect of cutting pressure on the depth of cutting slit was investigated at different traverse rates. Note that the jet was directed perpendicularly to the steel plate.

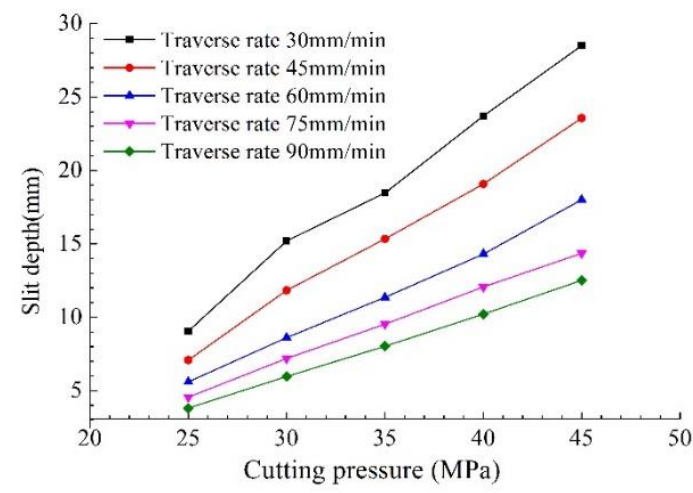

Figure 2. Effect of cutting pressure on slit depth
It can be seen from Figure 2 that the slit depth increased linearly with the rise of cutting pressure at different traverse rates. In light of the curves, the regression equations between cutting pressure and slit depth were derived (Table 2).

Table 2. Regression equations between cutting pressure and slit depth

\begin{tabular}{c|l|c}
\hline $\begin{array}{c}\text { Traverse } \\
\text { rate }(\mathrm{mm} / \mathrm{min})\end{array}$ & $\begin{array}{c}\text { Regression } \\
\text { equation }\end{array}$ & $\begin{array}{c}\text { Pressure } \\
\text { threshold(MPa) }\end{array}$ \\
\hline 30 & $h=0.948 P-14.185$ & 14.963 \\
45 & $h=0.805 P-12.781$ & 15.877 \\
60 & $h=0.610 P-9.786$ & 16.239 \\
75 & $h=0.489 P-7.582$ & 15.505 \\
90 & $h=0.433 P-7.059$ & 16.303 \\
\hline
\end{tabular}

Table 2 shows the existence of a pressure threshold at each traverse rate. The steel plate was not eroded as long as the cutting pressure of the jet stayed below the threshold. Through comparison, it is observed that the pressure thresholds are similar at different traverse rate, indicating that the threshold is not related to the traverse rate.

\subsection{Effect of jet angle on slit depth}

The jet angle refers to the angle between the jet direction and the traverse direction of the nozzle (Figure 3).

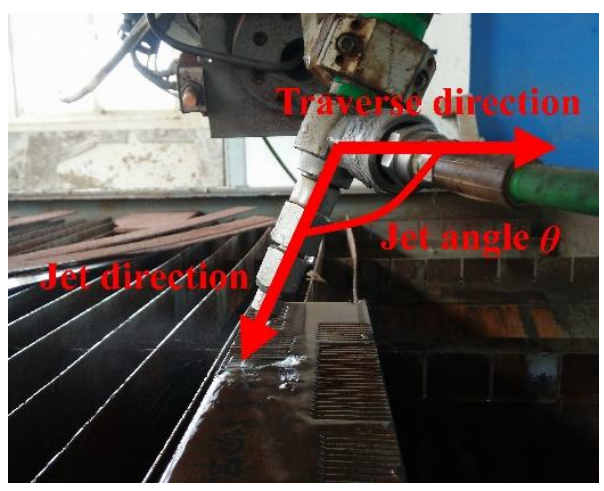

Figure 3. The jet angle

The effect of jet angle on slit depth was studied at the traverse rates of $30 \mathrm{~mm} / \mathrm{min}, 60 \mathrm{~mm} / \mathrm{min}$ and $90 \mathrm{~mm} / \mathrm{min}$ and the cutting pressure of $40 \mathrm{MPa}$. The other parameters are the same as shown in Table 1. Then, the relationship between the jet angle and slit depth was plotted (Figure 4) according to the measured results.

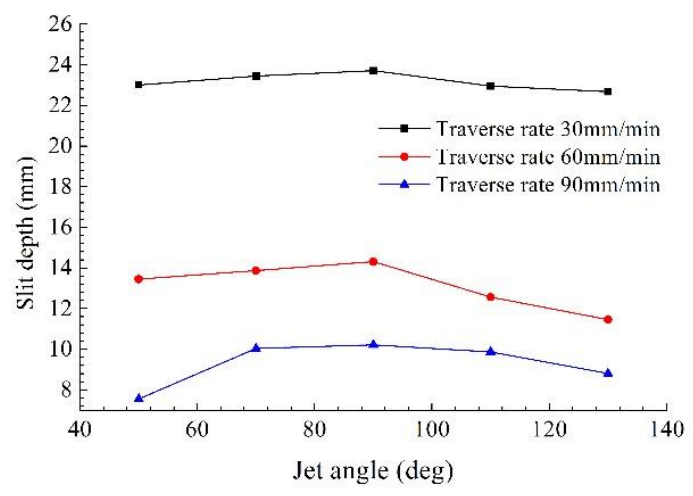

Figure 4. Effect of the jet angle on the cutting depth 
As shown in Figure 4, the optimal jet angle for Q345 steel was around $80^{\circ}$, that is, the AWJ has the strongest cutting ability at this angle.

The above pre-mixed AWJ cutting experiments reveal the effect of different parameters on the slit depth. The findings are directly related to the motion features of the AWJ, the key to understanding the AWJ cutting mechanism. In view of the difficulty in capturing the high-speed micro erosion during the AWJ cutting, a numerical simulation will be carried out to analyse the motion features of the AWJ.

\section{PRE-MIXED AWJ CUTTING SIMULATION}

\subsection{Theoretical basis (SPH)}

Proposed by Lucy [22], Gingold and Monahan [23], the SPH can handle partial differential equations based on Lagrange method. By this method, the computing domain is discretized into numerous particles, such that the divergence and distortion problems can be solved for large deformation simulations.

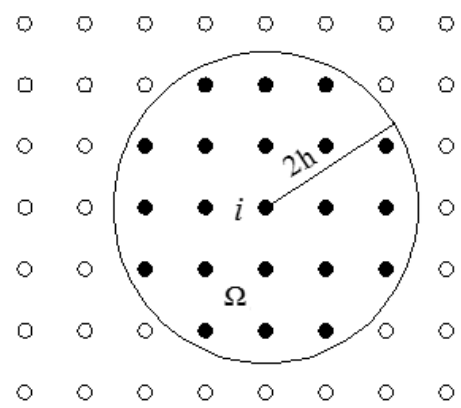

Figure 5. Support domain $\Omega$ with a radius of $2 h$ for particle $i$

As shown in Figure 5, with the kernel function $W(x-y, h)$, the value of interpolation function $f(x)$ at particle $i$ can be expressed as the sum of the interpolation function values of other particles in the support domain $\Omega$ with a radius of variable smoothing length $2 h$ [24].

$f\left(x_{i}\right)=\sum_{j=1}^{N} \frac{m_{j}}{\rho_{j}} f\left(x_{j}\right) W\left(x_{i}-x_{j}, h\right)$

The continuity, momentum and energy equations can be derived by time differential processing, when the interpolation function respectively represents density, velocity, and energy field. The three equations can be expressed as [20]:

$$
\frac{\mathrm{d} \rho_{i}}{\mathrm{~d} t}=\sum_{j=1}^{N} m_{j}\left(v_{i}-v_{j}\right) \nabla_{i} W\left(x_{i}-x_{j}, h\right)
$$

$$
\frac{\mathrm{d} v_{i}}{\mathrm{~d} t}=\sum_{j=1}^{N} m_{j}\left(\frac{p_{i}}{\rho_{i}^{2}}+\frac{p_{j}}{\rho_{j}^{2}}+\prod_{i j}\right) \nabla_{i} W\left(x_{i}-x_{j}, h\right)
$$

$$
\frac{\mathrm{d} e_{i}}{\mathrm{~d} t}=\frac{1}{2} \sum_{j=1}^{N} m_{j}\left(\frac{p_{i}}{\rho_{i}^{2}}+\frac{p_{j}}{\rho_{j}^{2}}+\Pi_{i j}\right) v_{i j} \nabla_{i} W\left(x_{i}-x_{j}, h\right)
$$

where $v_{i j}=\left(v_{i}-v_{j}\right) ; \Pi_{i j}$ is the artificial viscosity.

\subsection{Material models}

During the simulation, the AWJ and the steel plate were simulated by different material models. Taking water as NULL material, the water equation was defined as the MieGruneisen equation of state [25].

$P=\frac{\rho_{o} C^{2} \mu\left[1+\left(1-\frac{\gamma_{O}}{2}\right) \mu-\frac{a}{2} \mu^{2}\right]}{\left[1-\left(S_{1}-1\right) \mu-S_{2} \frac{\mu_{2}}{\mu+1}-S_{3} \frac{\mu^{3}}{(\mu+1)^{2}}\right]}+\left(\gamma_{O}+a \mu\right) E a$

The parameter values of the above equation are listed in Table 3.

Table 3. Parameter values of the Mie-Grueisen equation of state

\begin{tabular}{cc}
\hline Mie-Grueisen equation Parameters & Values \\
\hline Sonic velocity, $C /\left(\mathrm{m} \cdot \mathrm{s}^{-1}\right)$ & 1480 \\
\hline Grueisen coefficient $r_{0}$ & 0.4934 \\
\hline Volume correction factor $a$ & 1.397 \\
\hline Fitting coefficient $S_{1}$ & 2.56 \\
\hline Fitting coefficient $S_{2}$ & -1.986 \\
\hline Fitting coefficient $S_{3}$ & 0.2268 \\
\hline Water density $\rho_{0} /\left(\mathrm{kg} \cdot \mathrm{m}^{-3}\right)$ & 1000 \\
\hline
\end{tabular}

The abrasive particles are made of the elastic-plastic material of $80 \#$ corundum. The properties of the particles were demonstrated by a linear-elastic material model. The parameter values are presented in Table 4.

Table 4. Properties of the abrasive particles

\begin{tabular}{cc}
\hline Parameters & Values \\
\hline Abrasive density $/\left(\mathrm{kg} \cdot \mathrm{m}^{-3}\right)$ & 3970 \\
\hline Elastic Modulus $/ \mathrm{GPa}$ & 450 \\
\hline Poisson's ratio & 0.25 \\
\hline
\end{tabular}

In light of the difference in material properties, the abrasive particles and the water were simulated as different SPH particles. To reflect the mixing situation of the abrasive particles and the water in the AWJ, the spatial distributions of the two SPH particles were determined by a random distribution program. The number of each type of SPH particles depends on their volume concentration and the total number of SPH particles.

Table 5. Properties of Q345 steel

\begin{tabular}{cc}
\hline Parameters & Values \\
\hline Steel type & Q345 \\
Steel density/(kg. $\left.\mathrm{m}^{-3}\right)$ & 7850 \\
Elastic Modulus/GPa & 212 \\
Poisson's ratio & 0.31 \\
Yield Strength/MPa & 345 \\
Tensile strength/MPa & 586 \\
Failure strain & 0.25 \\
\hline
\end{tabular}

Considering the plastic property of the metallic material and its hardening in the deformation process, a plastic hardening model was introduced to define the plasticity of Q345 steel. 
The model is targeted at the nonlinear plastic hardening body. Then, the equivalent failure strain was also introduced. Once its strain exceeds the equivalent failure strain, the metallic material should be removed from the subsequent calculation. In this way, the material erosion failure was simulated. The properties of Q345 steel are recorded in Table 5.

\subsection{SPH-FEM coupled model}

During the simulation, the Q345 steel plate was simulated by the FEM, while the jet was simulated by the SPH due to its large deformation. The FEM model for the steel plate and the SPH model for the AWJ were coupled by the contact algorithm [19]. The type of steel-jet contact is CONTACT_ERODING_NODES_TO_SURFACE in LSDYNA.

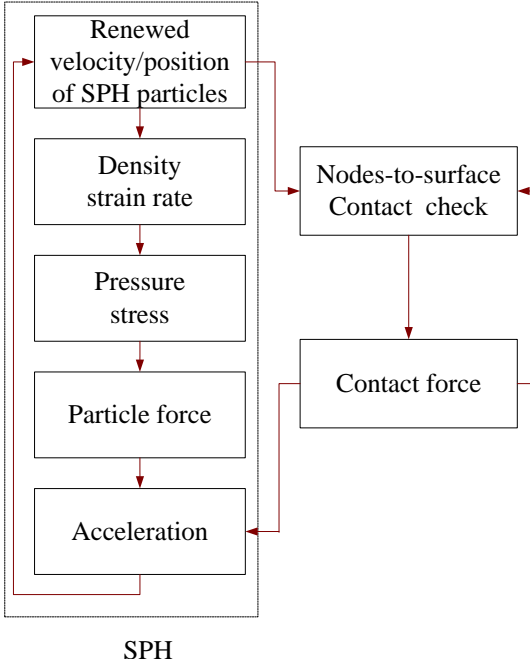

Figure 6. Coupling between SPH and FEM

\subsection{Jet velocities under different pressures}

During the SPH simulation of the AWJ, it is necessary to define the velocities of the SPH particles. Since the flow rate of the jet varies with pressures, the jet velocity must be different under different pressures. Thus, the average jet velocity at the nozzle outlet was obtained by measuring the flow rate of jet under different pressures.

Table 6. Jet velocities under different pressures

\begin{tabular}{c|c}
\hline Pressure $(\mathrm{MPa})$ & Jet velocity $(\mathrm{m} / \mathrm{s})$ \\
\hline 15 & 65.58 \\
25 & 98.97 \\
30 & 110.45 \\
35 & 133.33 \\
40 & 150.03 \\
45 & 166.66 \\
\hline
\end{tabular}

\subsection{Simulation model of AWJ erosion}

The AWJ erosion was simulated by the model shown in Figure 7. The length of SPH particle column was set to different values according to the jet velocities, so that the erosion time was kept at $0.3 \mathrm{~ms}$.

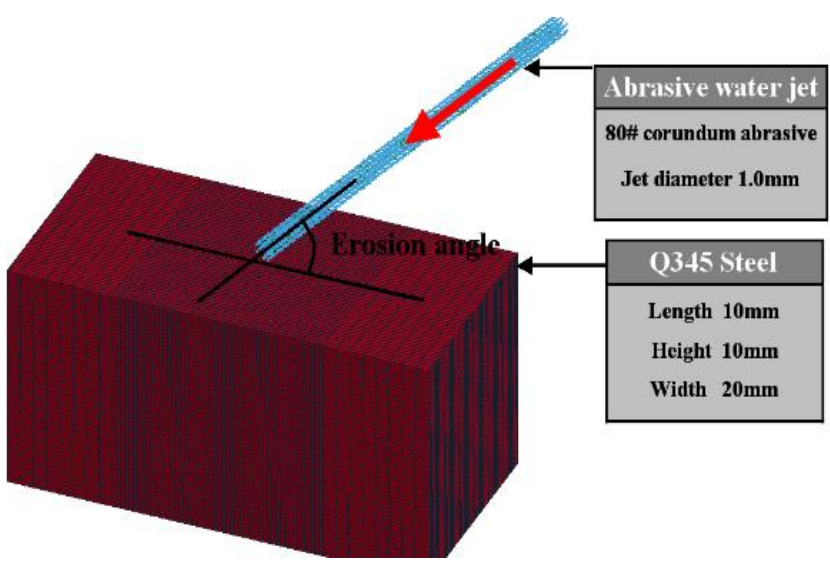

Figure 7. Simulation model of AWJ erosion

\section{SIMULATION OF AWJ EROSION}

\subsection{Erosion under different pressures}

The AWJ erosion models were set up under different jet pressures, using the SPH velocities in Table 6. Then, the cutting experiments were carried out under different pressures at the jet angle of $90^{\circ}$. To reveal the effect of jet pressure, all the other parameters were maintained constant. At the same traverse rate of the jet, the erosion time was always kept at $0.3 \mathrm{~ms}$ at different positions of the Q345 steel plate. The lengths $L$ of the SPH particle column was calculated according to the erosion time and jet velocities (Table 7). The simulation results under different pressures are displayed in Figure 8.

Table 7. Lengths of SPH particle column under different pressures

\begin{tabular}{c|c}
\hline Jet pressure $(\mathrm{MPa})$ & Length of SPH particle column $(\mathrm{mm})$ \\
\hline 15 & 19.5 \\
25 & 30.0 \\
30 & 33.0 \\
35 & 39.0 \\
40 & 45.0 \\
45 & 49.5 \\
\hline
\end{tabular}
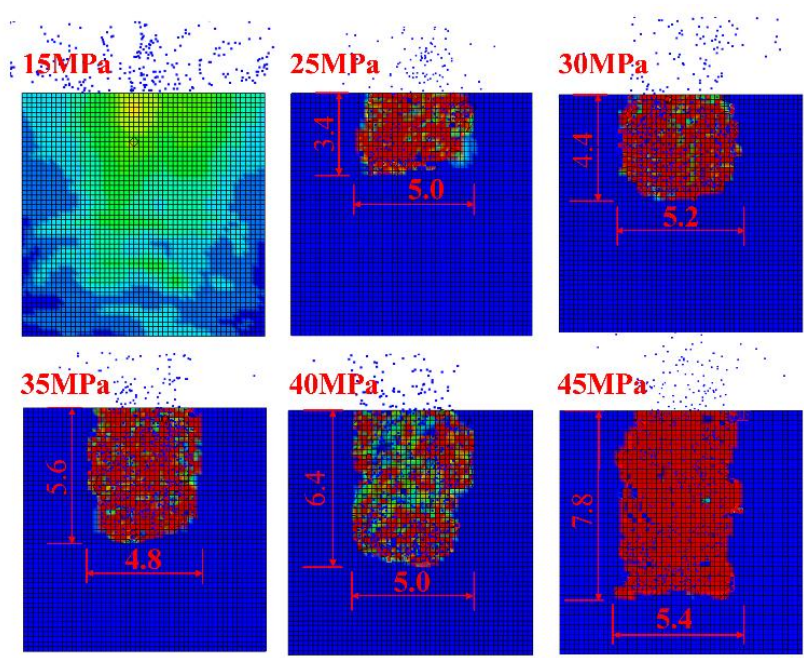

$45 \mathrm{MPa}$

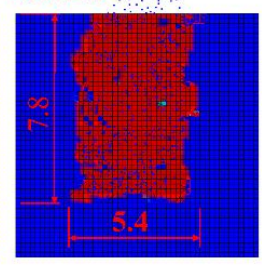

Figure 8. Simulation results under different pressures

As shown in Figure 8, the depth and width of the erosion craters varied with the jet pressures. No erosion was observed 
on the steel plate at $15 \mathrm{MPa}$. This is because the abrasive particles did not have enough erosion kinetic energy to damage the steel. The cutting experiments show that, under the action of 80-mesh brown corundum abrasives, the pressure threshold for Q345 steel fell between $15 \mathrm{MPa}$ and $17 \mathrm{MPa}$. The simulation results agree well with the experimental results.

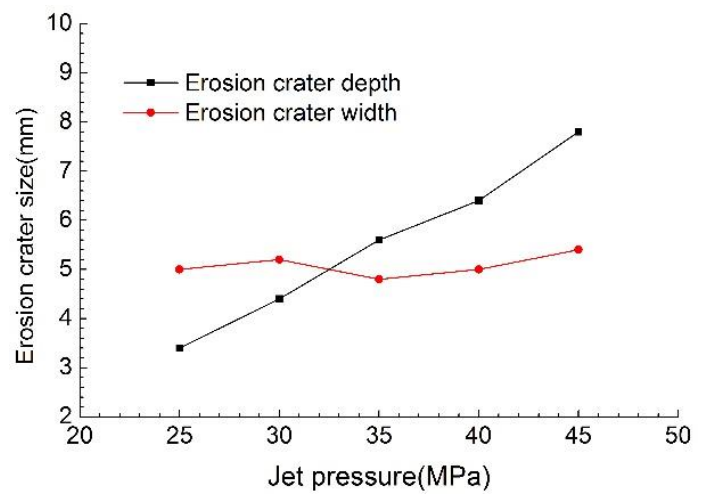

Figure 9. Depth and width of erosion craters under different pressures

According to Figures 8 and 9, the depth of erosion crater increased with the jet pressure under the same erosion time, when the pressure fell between $25 \mathrm{MPa}$ and $45 \mathrm{MPa}$. This trend is attributable to the dependence of the crater depth on the vertical erosion of the AWJ. In fact, the vertical erosion velocity is positively correlated with the ability of the jet to erode the bottom material of the crater. Figure 9 shows a linear relationship between the erosion crater depth and the jet pressure, which is consistent with the experimental results.

It can also be observed from Figures 8 and 9 that the erosion crater width exhibited some irregular fluctuations with the change of jet pressure. Considering the limited effect of the jet pressure, it is rational to say that the width of erosion crater remained the same under different jet pressures. When the jet moves upwards from the bottom of the erosion crater, secondary erosion will be produced on the wall of the erosion crater. Actually, the erosion crater width is influenced by both the jet diameter and the secondary erosion of the jet. Here, the jet diameter is assumed to be the diameter of the nozzle outlet, because the target distance and jet divergence are so small as negligible. Thus, the fluctuation of erosion crater width is mainly resulted from the secondary erosion of the jet. If the crater is deep enough, the secondary erosion will be weak in the upper part of the material. This explains why the width of the erosion crater remained basically constant under different jet pressures.

\subsection{Erosion at different jet angles}

Figure 10 shows the simulation results at the jet angles of $50^{\circ}, 70^{\circ}$ and $90^{\circ}$, the erosion time of $0.3 \mathrm{~ms}$ and the jet pressure of $40 \mathrm{MPa}$.
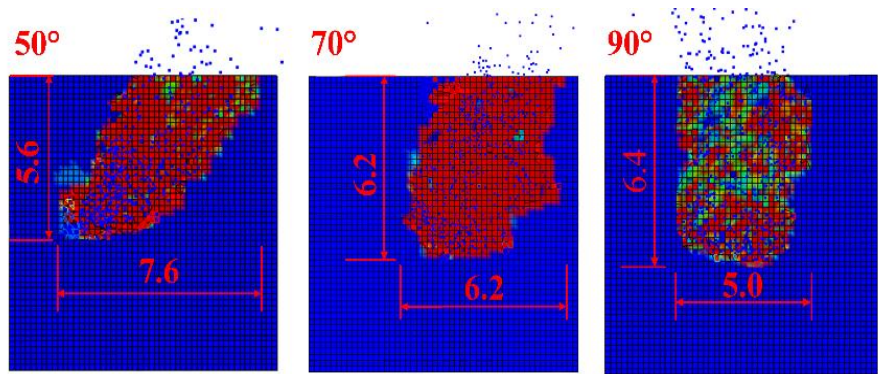

Figure 10. Simulation results at different jet angles

It is clear that the jet angle has a major impact on the shape of the erosion crater. As the jet angle decreased, the vertical velocity of the jet exhibited a gradual decrease, while the horizontal velocity of the jet underwent a gradual increase. Thus, the vertical erosion kinetic energy was in the decline, while the horizontal erosion kinetic energy was on the rise. Because of these trends, the erosion crater became shallower in the vertical direction and more uneven in the horizontal direction. Moreover, the horizontal erosion kinetic energy altered the secondary erosion features of the jet, such that the inner wall of the crater was eroded more seriously in the traverse direction, thus forming a sloping erosion crater.
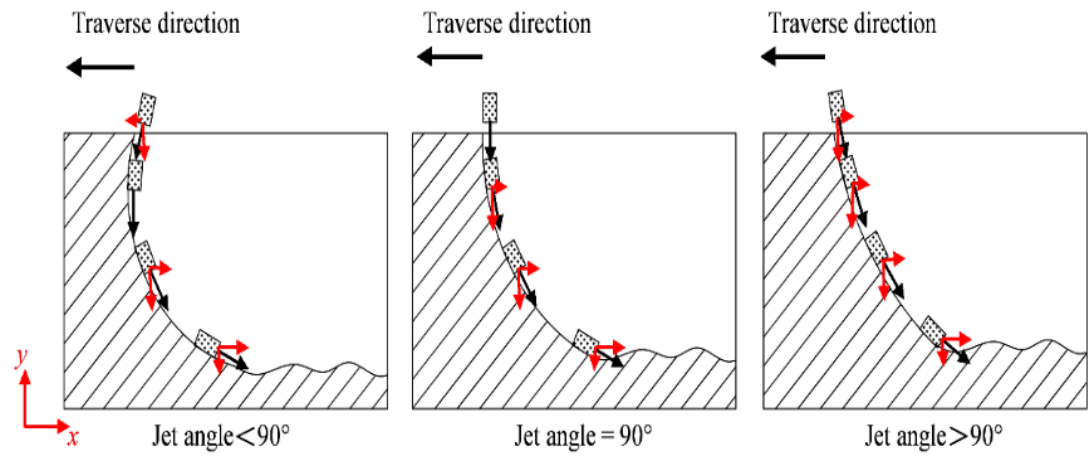

Figure 11. Erosion at different jet angles

As can be seen from Figure 11, the AWJ was reflected to the material-free side with the increase of erosion depth, causing jet deflection and the change of the jet angle [26]. In this case, the erosion ability of the jet changed in the vertical direction, which in turn affected the cutting depth.

When the jet angle was smaller than $90^{\circ}$, the jet had a horizontal velocity in the transverse direction. The horizontal velocity counteracted the jet deflection trend and slowed down the decrease of the jet velocity component in the vertical direction, thus deepening the cutting depth. Any further reduction in the jet angle would decrease the jet velocity component in the vertical direction and weaken the jet erosion ability in the vertical direction, resulting in a decline of the cutting depth. These interactions can explain the experimental results in Figure 4: the cutting depth first increased and then decreased with the decrease of the jet angle, provided that the 
angle is smaller than $90^{\circ}$.

After the jet angle surpassed $90^{\circ}$, the jet had a horizontal velocity opposite to the traverse direction, which accelerated the deflection trend and reduced the cutting depth. This is consistent with the trend in Figure 4.

\section{CONCLUSIONS}

This paper analyses the effects of jet pressure and angle on the cutting depth of Q345 steel through several experiments. The AWJ erosion simulation model was established through the coupling of the SPH and the FEM. Then, the effects of jet pressure and angle on the cutting depth were discussed according to the features of the jet flow and its impacts on the morphology of the erosion crater. The main conclusions of this research are as follows:

First, the jet pressure has a positive linear correlation with the cutting depth. During the AWJ cutting, there exists a pressure threshold, i.e. the jet pressure under which the abrasive erosion kinetic energy is just enough to induce material deformation. For the 80-mesh corundum abrasive particles, the pressure threshold of Q345 steel falls in the range of $15 \mathrm{MPa}$ to $17 \mathrm{MPa}$.

Second, the Q345 steel suffers from deformation and failure under the high-frequency and high-speed impinging of abrasive particles. The abrasive velocity is positively correlated with the erosion ability of the abrasive particles to induce material failure.

Third, the variation in the jet angle changes the vertical and horizontal jet velocities. The change of vertical velocity will affect the cutting depth, while that of the horizontal velocity will alter the secondary erosion features of the jet on the crater wall.

Fourth, the horizontal velocity in the transverse direction can counteract the jet deflection trend and slow down the decrease of the jet velocity component in the vertical direction, thus deepening the cutting depth. For Q345 steel, the optimal jet angle is about $80^{\circ}$.

\section{ACKNOWLEDGEMENTS}

This work is supported by the Chongqing Research Program of Basic Research and Frontier Technology (No. cstc2017jcyjAX0166).

\section{REFERENCES}

[1] Li HZ, Wang J. (2015). An experimental study of abrasive waterjet machining of Ti-6Al-4V. International Journal of Advanced Manufacturing Technology 81(1-4): 361-369. https://doi.org/ 10.1007/s00170-015-7245-5

[2] Ramesha N, Hatna S, Akhtar S. (2016). Abrasive water jet machining and mechanical behavior of banyan tree saw dust powder loaded polypropylene green composites Polymer Composites 37(6): 1754-1764. https://doi.org/ $10.1002 /$ pc. 23348

[3] Sasidharan S, Warrier KGK, Hareesh US, Karnan B, Uthayakumar M. (2017). Mathematical modelling on multiple variables in machining LaPO4/ Y2O3composite by Abrasive waterjet. International Journal of Machining and Machinability of Materials 19(5): 426-439. https://doi.org/ 10.1504/IJMMM.2017.087616

[4] Hejjaji AA, Zitoune R, Crouzeix L, Roux SL, Collombet F. (2017). Surface and machining induced damage characterization of abrasive water jet milled carbon/epoxy composite specimens and their impact on tensile behavior. Wear 376-377: 1356-1364. https://doi.org/ 10.1016/j.wear.2017.02.024

[5] Li GR, Ge YF, Zheng Y, Xue XQ. (2015). The research of stress theoretical analysis and structural parameters of sprayer fluid of rotating conical abrasive jet. International Journal of Heat and Technology 33(4): 3340 .

[6] Jackson MJ, Davim JP. (2011). Machining with Abrasives. Springer, New York, 85. https://doi.org/10.1007/s00170-016-9564-6

[7] Zhang XC, Zhou CL, Jiang LY, Guo R. (2017). Influence of process parameters on abrasive particle motion characteristics in abrasive water jet descaling. International Journal of Advanced Manufacturing Technology 90(9-12): 2741-2749. https://doi.org/ 10.1016/ j.mspro.2014.07.017

[8] Wen ZH, Liu Y, Liu XT, Liang B. (2017). Experimental research into the effects of abrasive characteristics on abrasive gas jet coal-breaking performance. International Journal of Heat and Technology 35(1): 32-36. https://doi.org/10.1016/j.ijmachtools.2013.01.003

[9] Deng SS, Guo LH, Guan JF, Guo GD, Yang X. (2016). Research on the prediction model for abrasive water jet cutting based on GA-BP neural network. Chemical Engineering Transactions 51: 1297-1302. https://doi.org/ 10.1016/ j.mspro.2014.07.094

[10] Gupta V, Pandey PM, Garg MP, Khanna R, Batra NK. (2014). Minimization of kerf taper angle and kerf width using Taguchi's method in abrasive water jet machining of marble. Procedia Materials Science 6: 140-149. https://doi.org/10.1016/j.proeng.2016.06.667

[11] Billingham J, Miron CB, Axinte DA, Kong MC. (2013). Mathematical modelling of abrasive waterjet footprints for arbitrarily moving jets: Part II-Overlapped single and multiple straight paths. International Journal of Machine Tools and Manufacture 68(68): 30-39. https://doi.org/ 10.1007/s00170-014-6404-4

[12] Aich U, Banerjee S, Bandyopadhyay A, Das PK. (2014). Abrasive water jet cutting of borosilicate glass. Procedia Materials Science 6: 775-785. https://doi.org/ 10.1007/ BF02317567

[13] Löschner P, Jarosz K, Niesłony P. (2016). Investigation of the effect of cutting speed on surface quality in abrasive water jet cutting of $316 \mathrm{~L}$ stainless steel. Procedia Engineering 149: 276-282. https://doi.org/ 10.1016/ j.wear.2015.08.022

[14] Wu YQ, Zhang SJ, Wang S, Yang FL, Tao H. (2015). Method of obtaining accurate jet lag information in abrasive water-jet machining process. International Journal of Advanced Manufacturing Technology 76(912): 1827-1835. https://doi.org/ 10.1016/j.powtec.2015.07.044

[15] Hashish M. (1988). Visualization of the abrasive-waterjet cutting process, Experimental Mechanics. 28(2): 159169. https://doi.org/ 10.3303/CET1759024

[16] Ansari MM, Chakrabarti A, Iqbal MA. (2016). Effects of impactor and other geometric parameters on impact behavior of FRP laminated composite plate. Modelling, Measurement and Control A 89(1): 25-44. 
https://doi.org/10.1007/ s40430-017-0707-y

[17] Azimian M, Schmitt P, Bart HJ. (2015). Numerical investigation of single and multi-impacts of angular particles on ductile surfaces. Wear 342-343: 252-261. https://doi.org/ 10.1086/112164

[18] Guo LH, Deng SS, Yang X. (2016). Numerical simulation of abrasive water jet cutting chemical pipeline based on SPH coupled FEM. Chemical Engineering Transactions 51: 73-78. https://doi.org/ 10.1093/mnras/181.3.375

[19] Liu XH, Liu SY, Ji HF. (2015). Numerical research on rock breaking performance of water jet based on SPH. Powder Technology 286: 181-192. https://doi.org/ 10.1007/ s00170-011-3495-z

[20] Deng SS, Chen XC, Guan JF, Chen ZL, Chen M, Liu Q. (2017). Research on the Effect of Jet Angle on Pre-Mixed Abrasive Water Jet Erosion Process. Chemical Engineering Transactions 59: 139-144. https://doi.org/ 10.1016/ S0045-7825(99)00442-9

[21] Chen XC, Deng SS, Guan JF, Hua WX. (2017). Experiment and simulation research on abrasive water jet nozzle wear behavior and anti-wear structural improvement. Journal of the Brazilian Society of Mechanical Sciences and Engineering 39(6): 2023-2033. https://doi.org/ 10.16078/ j.tribology.2018.01.002

[22] Lucy LB. (1977). A numerical approach to the testing of the fission hypothesis. Astronomical Journal 82: 10131024. https://doi.org/ 10.1086/112164

[23] Gingold RA, Monahan JJ. (1977). Smoothed particle hydrodynamics: Theory and application to nonspherical stars. Monthly Notices of the Royal Astronomical Society $\quad 181(3)$ : 375-389. https://doi.org/10.1093/mnras/181.3.375

[24] Yu F, Wang JM, Liu FH. (2012). Numerical simulation of single particle acceleration process by SPH coupled FEM for abrasive waterjet cutting. International Journal of Advanced Manufacturing Technology, 59(1): 193-200. https://doi.org/ 10.1007/s00170-011-3495-z

[25] Campbell J, Vignjevic R, Libersky L. (2000). A contact algorithm for smoothed particle hydrodynamics. Computer Methods in Applied Mechanics and Engineering 184(1): 49-65. https://doi.org/ 10.1016/S0045-7825(99)00442-9

[26] Chen XC, Deng SS, Guan JF, Chen M, Chen Y. (2018). Characteristics and generation mechanism of metal damage morphology by abrasive water jet erosion. Mocaxue Xuebao/Tribology 38(1): 8-16. https://doi.org/ $10.16078 /$ j.tribology.2018.01.002 